\title{
Design and Parameter Study of a Self-Compensating Hydrostatic Rotary Bearing
}

\author{
Xiaobo Zuo, Shengyi Li, Ziqiang Yin, and Jianmin Wang \\ College of Mechatronics Engineering \& Automation, National University of Defense Technology, Changsha 410073, China \\ Correspondence should be addressed to Shengyi Li; engineerzuo@163.com
}

Received 7 April 2013; Accepted 20 September 2013

Academic Editor: Shigenao Maruyama

Copyright ( 2013 Xiaobo Zuo et al. This is an open access article distributed under the Creative Commons Attribution License, which permits unrestricted use, distribution, and reproduction in any medium, provided the original work is properly cited.

\begin{abstract}
The influence of design parameters on the static performance of a newly designed self-compensating hydrostatic rotary bearing was investigated. The bearing was designed by incorporating the main attributes of angled-surface self-compensating bearing and opposed-pad self-compensating bearing. A governing model based on flow conservation was built to theoretically study the static performance, and the methodology was validated by experiments. It is pointed out that the influence factors on the bearing static performance are the designed resistance ratio of the restricting land to the bearing land, the inner resistance ratio of the land between pockets to that between the pocket and the drain groove, the initial clearance ratio of the restricting gap to the bearing gap, and the semiconical angle. Their effects on the load carrying capacity and stiffness were investigated by simulation. Results show that the optimum designed resistance ratio is 1 ; the initial clearance ratio should be small, and the inner resistance ratio should be large.
\end{abstract}

\section{Introduction}

Hydrostatic bearings are widely used in high precision mechanisms and machines for the advantage of low friction, high stiffness, high accuracy, and long life. The pressure in the hydrostatic bearings is generated by external pumps, and compensation devices are necessary to regulate flow into the pockets. Garg et al. [1] presented a review on the design and development of hybrid/hydrostatic bearings, in which researches on the compensation devices are reviewed. Martin [2] summarized the operational principle of constant-flow and constant pressure restrictors. Malanoski and Loeb [3] theoretically investigated the compensation effects of capillary, orifice, and constant-flow restrictor on the static stiffness of hydrostatic thrust bearing. Sharma et al. [4] studied the slot-entry hydrostatic/hybrid journal bearing using finite element method and revealed that asymmetric slot-entry journal bearings provide an improved stability threshold speed margin compared with asymmetric hole-entry journal bearings compensated by capillary, orifice, and constant-flow valve restrictors. Singh et al. [5] studied the performance of membrane compensated multirecess hydrostatic/hybrid journal bearing and found that selection of recess shape along with a suitable compensation device is needed to get an improved performance of the bearing. Kumar et al. [6] investigated the restrictor design parameter of capillary compensated journal bearings. Gao et al. $[7,8]$ analyzed the static and dynamic characteristics of hydrostatic guides with progressive mengen flow controller, in which the flow rate does not decrease with the increase of the pocket pressure so that the oil gap keeps constant and the dynamic stiffness is greatly improved. The influence of the controller parameters on the performance was also discussed. Kang et al. $[9,10]$ utilize a flow equilibrium method to study the effect of constant compensation and single-action variable compensation on open- and closed-type flat bearing. Hydrostatic bearings with these types of restrictors are widely used in industry; however, the external compensation devices add to the complexity of design and are sensitive to manufacturing errors.

Self-compensating bearings offer another design scheme. It does not need any external devices, which are substituted by some internal features, to achieve load carrying capacity. Hoffer [11] proposed an automatic pressure balancing bearing, using opposed gap as a means of regulating flow to the pockets on the opposite side of a bearing. In view of the main features, bearings of this type are called opposed-pad self-compensating bearings in this paper. Slocum et al. [1214] developed Hoffer's ideas and designed self-compensating 
hydrostatic linear motion bearing and journal bearing, using fluid lines to connect the annulus supply hole and the pocket on the opposite side. The linear motion bearing was designed as modular and can be lubricated by water, which is very favorable in machine tool applications. Wasson and Slocum [15] designed another self-compensating hydrostatic journal bearing in which the compensation feature is connected to the corresponding pocket via grooves on the surface of the bearing so that the external sleeve is nonessential. Kotilainen and Slocum [16] introduced a new manufacturing method of the bearing proposed by Wasson and Slocum [15], which is very cost effective because the cast processing is introduced. Kane et al. $[17,18]$ proposed a hydrostatic bearing with angled-surface self-compensation. The bearing consists of several round parts which can be easily manufactured and assembled and achieves high stiffness and accuracy. But the restricting gap is a whole circular cylinder region, in which the lubricate diffusion is inevitable, and the acute edge between the restricting region and the bearing region is prone to be damaged. Once it is broken, the relative two bearing pockets may be connected at the entrance. These disadvantages are harmful to the performance of the hydrostatic bearing.

For both the opposed-pad and the angled-surface selfcompensating bearings, performance is not much affected by the manufacturing errors. As the restriction is achieved by the gap which varies with the external load, the stiffness of self-compensating bearings is higher than that of the bearings with fixed restrictors. Another advantage of selfcompensating bearings is that they are far less sensitive to dirt because they have no small diameter passages. The angledsurface self-compensating design lends the bearing to low profile rotary tables, while the previous opposed-pad selfcompensating designs do not. In this study the angled-surface and the opposed-pad self-compensations are unified to form a hydrostatic rotary bearing. Analysis is based on flow equilibrium method. Design parameters are analyzed, and their effect on the load capacity and static stiffness is discussed.

\section{Bearing Design}

The key feature of the angled-surface self-compensating hydrostatic bearing is a restricting gap region that makes an acute angle relative to a bearing gap region. And the main feature of the opposed-pad self-compensating bearing is the restricting pocket on the opposite side of the bearing pocket. The restoring force in radial direction is reinforced for self-compensating bearings because the restricting gap adversely varies with the corresponding bearing gap. The design present in this paper incorporates the main attributes of angled-surface self-compensating bearings and opposedpad self-compensating bearings. The innovative feature is the restrictor units on the restricting surface which makes an acute angel relative to the bearing surface. Every bearing pocket has its respective restrictor unit, so the diffusion effect, which is inevitable in previous angled-surface selfcompensating bearing, is avoided. Meanwhile sharp acute edge which is prone to be broken is not necessary.

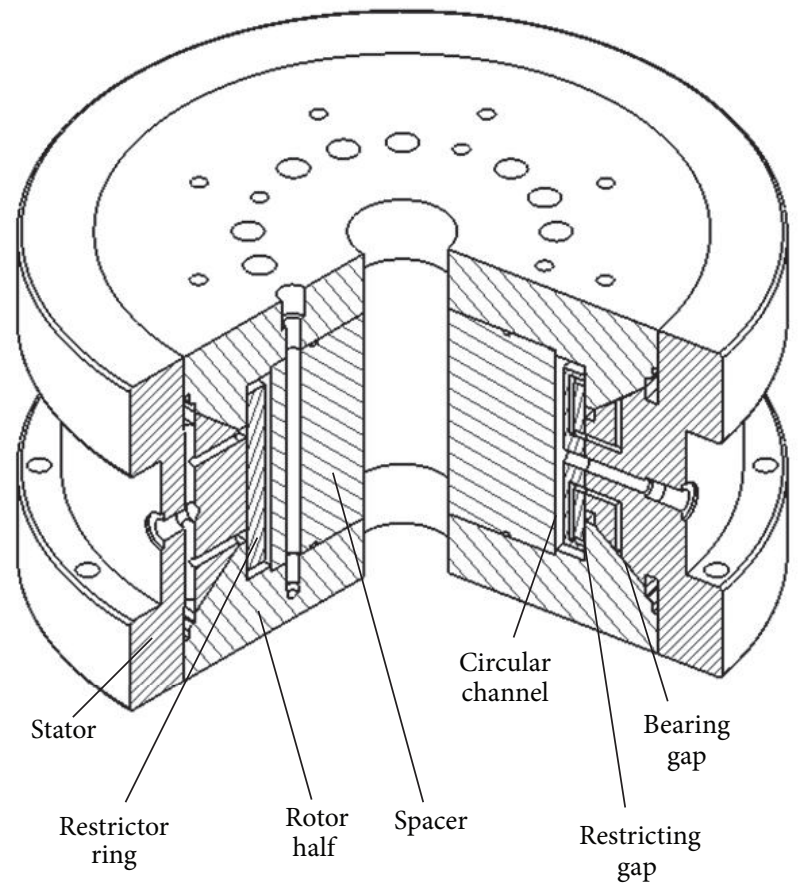

FIGURE 1: Framework of the designed bearing.

A sectional view of a rotary bearing which incorporates this concept is shown in Figure 1. The hydrostatic bearing includes a rotor assembly and a stator assembly. The rotor assembly is composed of two rotor halves and a spacer; the stator assembly is composed of a stator and a restrictor ring. The sectional view of the stator assembly is shown in Figure 2. Framework of the restrictor unit is illustrated by a broken view. The restrictor unit is composed of a supply groove, a restricting land, and a restrictor pocket. Every restrictor pocket is connected to a bearing pocket by drilling holes. Though the fabrication process must be a little more complicated, the improvement of the bearing performance may be considerable. Figure 3 displays the entity pictures of the bearing and its parts.

Then, fluid flow path through the bearing is described in detail according to Figures 1 and 2. After entering the bearing through the supply hole on the stator, the pressurized fluid fills the circular channel formed by the restrictor ring and the rotor assembly. Then, it flows into the restricting gap. There, it first fills the supply groove, and most fluid flows through the restricting land, where its pressure drops, and then into the restrictor pocket; the rest flows through the leakage land into the drain groove. The fluid in the restrictor pocket enters the corresponding bearing pocket via the fluid passage and then through the bearing gap into the drain groove, where its pressure drops to atmospheric. The atmospheric fluid is collected into the drain passage and finally flows out of the bearing through the drain hole. Depth of the pockets and the grooves should be greatly larger than the clearance of the restricting gap and the bearing gap to ensure that the pressure loss across them is negligible. 

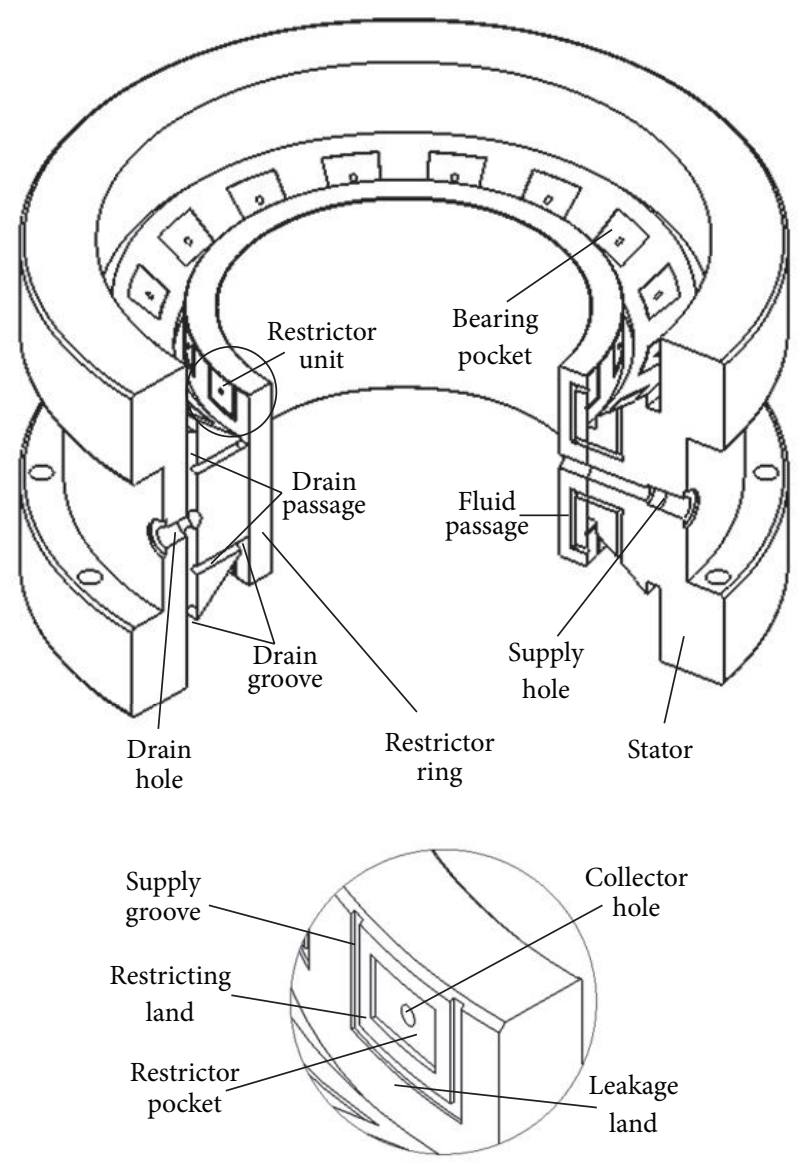

FIGURE 2: Sectional view of the stator assembly.

\section{Analysis}

3.1. Mathematical Model. The governing equation of the lubricant flow in the hydrostatic bearing is the Reynolds equation. Since the restricting surface is cylinderical and the bearing surface is conical, both forms in Cartesian coordinates and polar coordinates are needed which are shown as follows:

$$
\begin{gathered}
\frac{\partial}{\partial x}\left(\frac{h^{3}}{12 \eta} \frac{\partial p}{\partial x}\right)+\frac{\partial}{\partial z}\left(\frac{h^{3}}{12 \eta} \frac{\partial p}{\partial z}\right)=\frac{U}{2} \frac{\partial h}{\partial z}+\frac{\partial h}{\partial t} \\
\frac{1}{r} \frac{\partial}{\partial r}\left(\frac{r h^{3}}{12 \eta} \frac{\partial p}{\partial r}\right)+\frac{1}{r^{2} \sin ^{2} \alpha} \frac{\partial}{\partial \varphi}\left(\frac{h^{3}}{12 \eta} \frac{\partial p}{\partial \varphi}\right)=\frac{\Omega}{2} \frac{\partial h}{\partial \varphi}+\frac{\partial h}{\partial t}
\end{gathered}
$$

where $x, y, r$, and $\varphi$ are the coordinates in Cartesian and polar coordinate systems, respectively, $h$ is the fluid film thickness, $\eta$ is the fluid dynamic viscosity, $p$ is the fluid pressure, $U$ and $\Omega$ are the line and angular velocity, respectively, and $t$ is the time.

Lumped parameter method is adopted to model the bearing. The bearing is divided into regions where the flow can be approximated by fully developed laminar flow between two parallel plates. Using the analogy of electrical networks, the bearing area can be segmented into some discrete zones as shown in Figure 4, where $R_{r}$ is the restrictor resistance, $R_{b}$ is the resistance of the bearing land between the pocket and the drain groove, $R_{l}$ is the resistance of the bearing land between adjacent pockets, and subscript $i$ is the pocket number.

By using the pressure boundary conditions, the pressure in these two coordinates is expressed, respectively, as

$$
\begin{aligned}
& p_{C}=\left(\frac{\int_{x}^{a}\left(1 / h^{3}\right) d x}{\int_{0}^{a}\left(1 / h^{3}\right) d x}\right)\left(p_{1}-p_{2}\right)+p_{2}, \\
& p_{p}=\left(\frac{\int_{r_{2}}^{r}\left(1 / h^{3} r\right) d r}{\int_{r_{2}}^{r_{1}}\left(1 / h^{3} r\right) d r}\right)\left(p_{1}-p_{2}\right)+p_{2},
\end{aligned}
$$

where $a, r_{1}$, and $r_{2}$ are coordinates of the boundaries and $p_{1}$ and $p_{2}$ are the boundary pressure, as shown in Figure 5 .

Equation (2) can be simplified by treating the gap height $h$ as a constant in every divided zone so that integration of the cube of $h$ is not necessary. Thus, the resistance of a single zone is defined by the profile, expressed, respectively, as

$$
\begin{gathered}
R_{C}=\frac{12 \eta a}{w h^{3}}, \\
R_{p}=-\frac{12 \eta}{\varphi_{w} h^{3}} \ln \frac{r_{2}}{r_{1}} .
\end{gathered}
$$

Fluid film thickness varies with rotor motion. As shown in Figure 6, the fluid film thickness can be calculated by

$$
h=h_{0}-\delta_{r} \cos \phi_{i} \cos \theta-\delta_{z} \sin \theta,
$$

where $h_{0}$ is the initial gap clearance, $\delta_{r}$ is the radial displacement, $\delta_{z}$ is the axial displacement, $\phi_{i}$ is the position angle from the direction of $\delta_{r}$, and $\theta$ is the semicone angle of the bearing surface. For the restricting gap region, $\delta_{z}=0, \theta=0$.

The nondimensional fluid film thickness is given as

$$
\bar{h}=\frac{h}{h_{0}},
$$

where $h_{0}=h_{b 0}$ is the designed clearance of bearing gap.

So the nondimensional fluid film thickness in the bearing gap and the restricting gap is, respectively, written as

$$
\begin{gathered}
\bar{h}_{b}=1-\varepsilon \cos \phi_{i} \cos \theta-\zeta \sin \theta, \\
\bar{h}_{r}=\bar{h}_{r 0}+\varepsilon \cos \phi_{i},
\end{gathered}
$$

where $\bar{h}_{r 0}=h_{r 0} / h_{0}$ is the nondimensional initial restricting clearance, $\varepsilon=\delta_{r} / h_{0}$ is the nondimensional radial displacement, that is, eccentricity ratio, and $\zeta=\delta_{z} / h_{0}$ is the nondimensional axial displacement.

It is seen from the formula of flow resistance as in (3) that the gap flow resistance changes with the fluid film thickness. When the rotor moves relative to the stator, the fluid film thickness is as in (4), so the gap flow resistance can be calculated by

$$
R=\frac{R_{0} h_{0}^{3}}{\left(h_{0}-\delta_{r} \cos \phi_{i} \cos \theta-\delta_{z} \sin \theta\right)^{3}},
$$




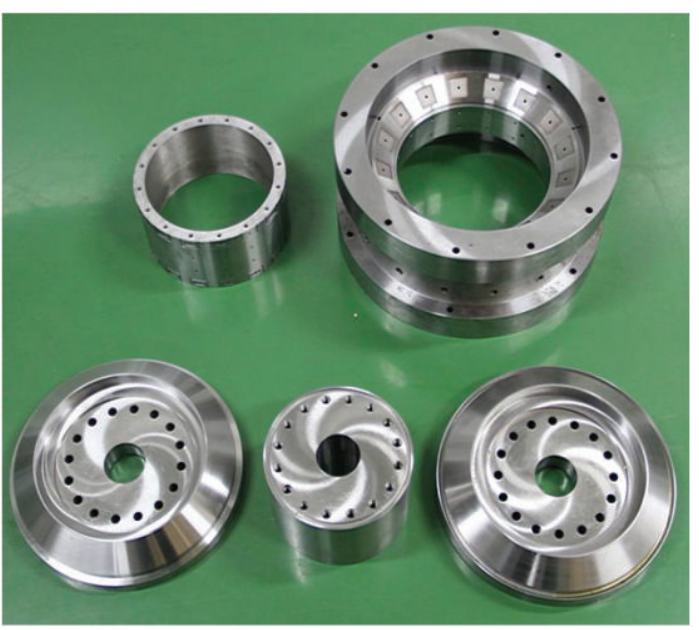

(a)

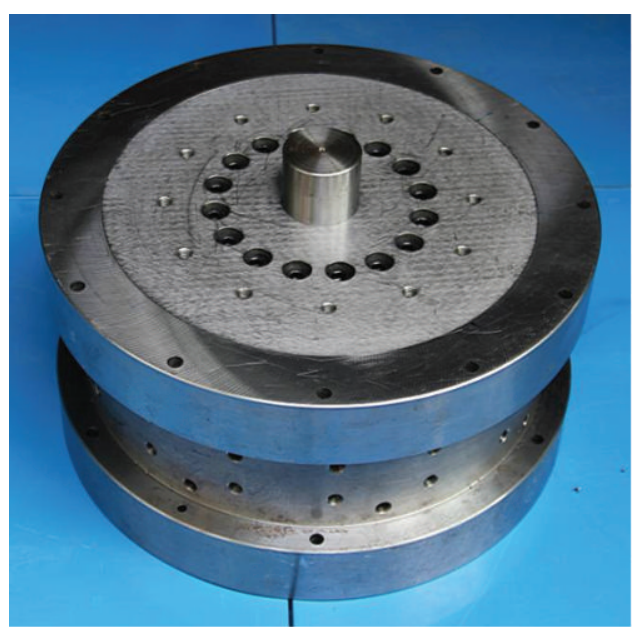

(b)

FIGURE 3: Manufactured parts and the assembled bearing.

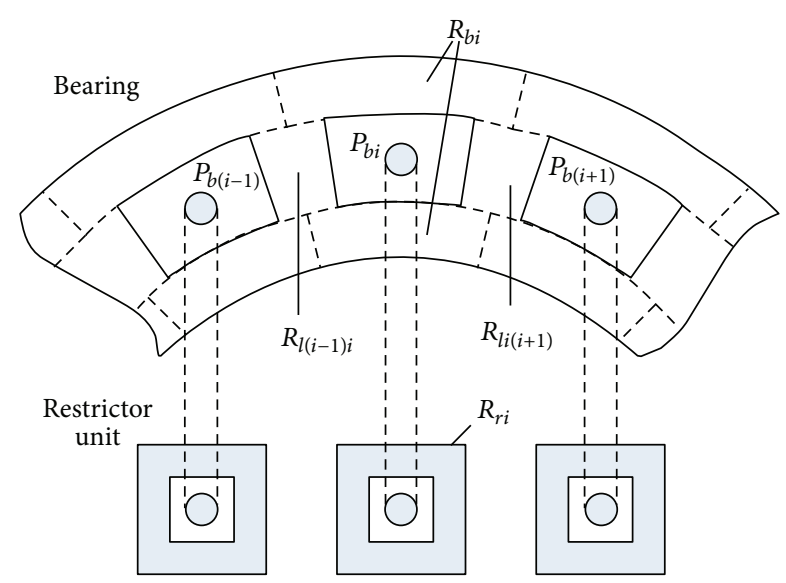

FIGURE 4: Sketch of the lumped parameter model.

where $R_{0}$ is the initial flow resistance of gap when no rotor displacement occurs.

The continuity condition is expressed as

$$
Q_{r i}=Q_{b i}+Q_{l i(i+1)}-Q_{l(i-1) i}
$$

where $Q_{r}$ is the flow rate getting into the restrictor pocket, $Q_{b}$ is the flow rate getting out of the bearing pocket, and $Q_{l}$ is the flow rate getting through the land between two adjacent pockets.

As the lumped parameter model is applied, the continuity condition can be written as

$$
\frac{p_{s}-p_{b i}}{R_{r i}}=\frac{p_{b i}}{R_{b i}}+\frac{p_{b i}-p_{b(i-1)}}{R_{l(i-1) i}}+\frac{p_{b i}-p_{b(i+1)}}{R_{l i(i+1)}},
$$

where $p_{s}$ is the supply pressure and $p_{b}$ is the pocket pressure. Then, $p_{b i}$ can be calculated by solving the equation set defined by (9).
3.2. Load Capacity and Stiffness. The load capacity of a single discrete bearing pocket region is calculated by

$$
F_{i}=p_{b i} A_{e}=\bar{F}_{i} p_{s} A_{e}
$$

where $A_{e}$ is the effective area of a discrete pocket region. The nondimensional load capacity is

$$
\bar{F}_{i}=\frac{p_{b i}}{p_{s}}
$$

and the nondimensional stiffness of the discrete region is

$$
\bar{j}_{i}=-\frac{\partial \bar{F}_{i}}{\partial \bar{h}} .
$$

The load capacity $\bar{W}$ and the stiffness $\bar{S}$ of the bearing equal the vector sum of $\bar{F}_{i}$ and $\bar{j}_{i}$ of all the divided regions in the corresponding direction, respectively.

3.3. Key Parameters. Next, the key parameters affecting the bearing static performance are discussed. By transposition, (9) can be rewritten as

$$
\begin{aligned}
p_{s}= & \left(1+\frac{R_{r i}}{R_{b i}}+\frac{R_{r i}}{R_{l i(i-1)}}+\frac{R_{r i}}{R_{l(i+1) i}}\right) p_{b i}-\frac{R_{r i}}{R_{l i(i-1)}} p_{b(i-1)} \\
& -\frac{R_{r i}}{R_{l(i+1) i}} p_{b(i+1)} .
\end{aligned}
$$

It indicates that the pocket pressure is affected by the resistance ratios. They are analyzed as follows:

$$
\begin{aligned}
\frac{R_{r i}}{R_{b i}} & =\frac{R_{r 0} h_{r 0}^{3}\left(h_{b 0}-\delta_{r} \cos \phi_{i} \cos \theta-\delta_{z} \sin \theta\right)^{3}}{R_{b 0} h_{b 0}^{3}\left(h_{r 0}-\delta_{r} \cos \phi_{i}\right)^{3}} \\
& =\lambda \frac{\left(1-\varepsilon \cos \phi_{i} \cos \theta-\varsigma \sin \theta\right)^{3}}{\left(1-\varepsilon \cos \phi_{i} / \bar{h}_{r 0}\right)^{3}},
\end{aligned}
$$




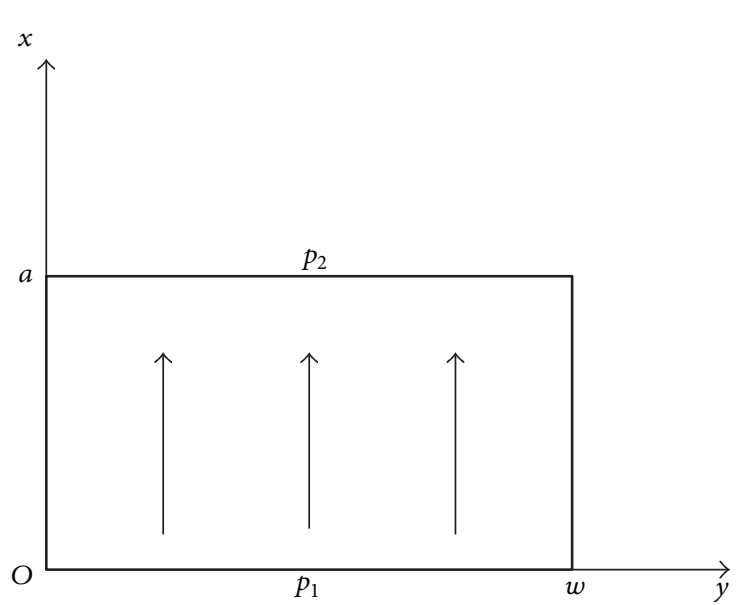

(a) Cartesian coordinate

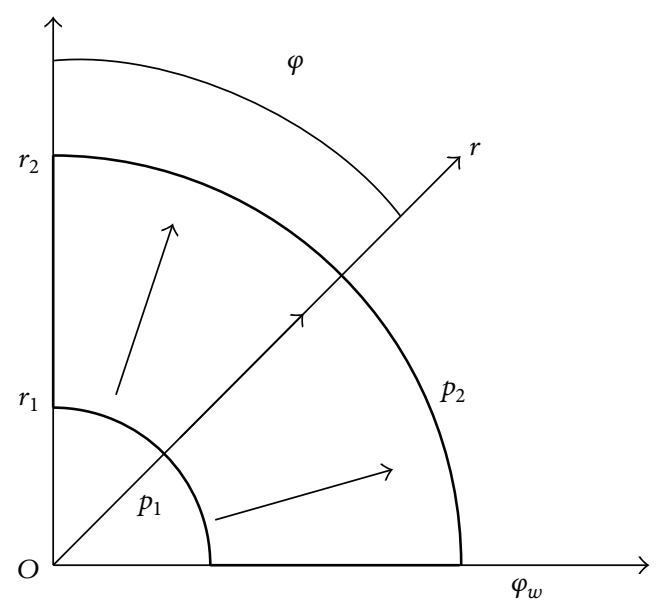

(b) Polar coordinate

FIGURE 5: Sketch of boundary conditions.
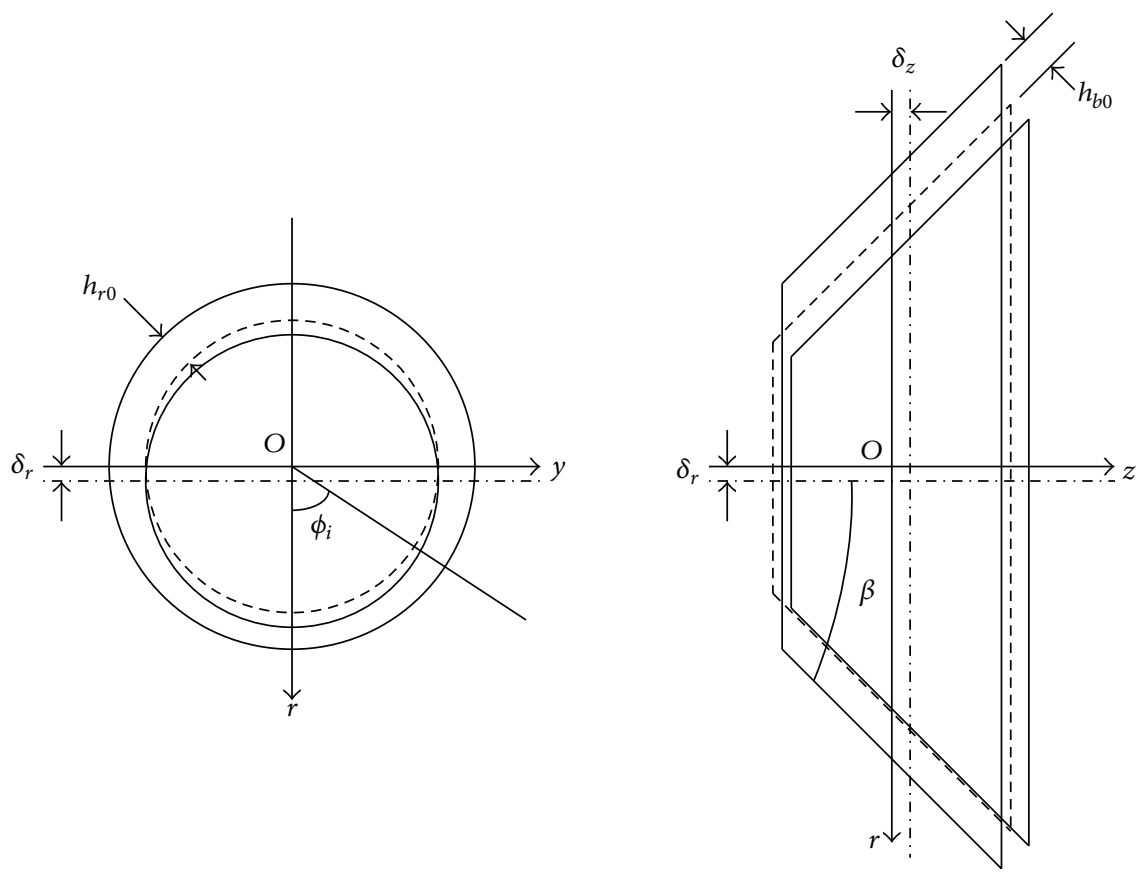

FIgURE 6: Schematic diagram of the fluid film thickness.

$$
\begin{aligned}
\frac{R_{r i}}{R_{l i(i+1)}} & =\frac{R_{r 0} h_{r 0}^{3}}{R_{b 0}\left(h_{r 0}-\delta_{r} \cos \phi_{i} \cos \theta\right)^{3}} \frac{R_{b 0}}{R_{l 0}} \frac{R_{l 0}}{R_{l i(i+1)}} \\
& =\frac{\lambda}{\kappa} \frac{\left(1-\varepsilon \cos \phi_{i(i+1)} \cos \theta-\varsigma \sin \theta\right)^{3}}{\left(1-\varepsilon \cos \phi_{i} \cos \theta / \bar{h}_{r 0}\right)^{3}} .
\end{aligned}
$$

$\lambda=R_{r 0} / R_{b 0}$ is the designed resistance ratio, which is a very important parameter of the bearing. $\kappa=R_{l 0} / R_{b 0}$ is the inner resistance ratio, which influences the lubricant diffusion between adjacent pockets. The larger the $\kappa$ is, the less the diffusion effect is. $\bar{h}_{r 0}=h_{r 0} / h_{b 0}$ is the nondimensional initial restricting clearance, that is, the initial clearance ratio of the restricting gap to the bearing gap. $\lambda$ and $\kappa$ are totally defined by the geometry. It can be summarized from (13) and (14) that the key parameters influencing the pocket pressure are the designed resistance ratio $\lambda$, the inner resistance ratio $\kappa$, the initial clearance ratio $\bar{h}_{r 0}$, and the semiconical angle $\theta$.

\section{Results and Discussion}

The influence of the most important design parameters on the bearing performance was simulated. Results indicate that the pocket number $n$ does not obviously affect the performance. It is because $n$ does not obviously change the total effective 


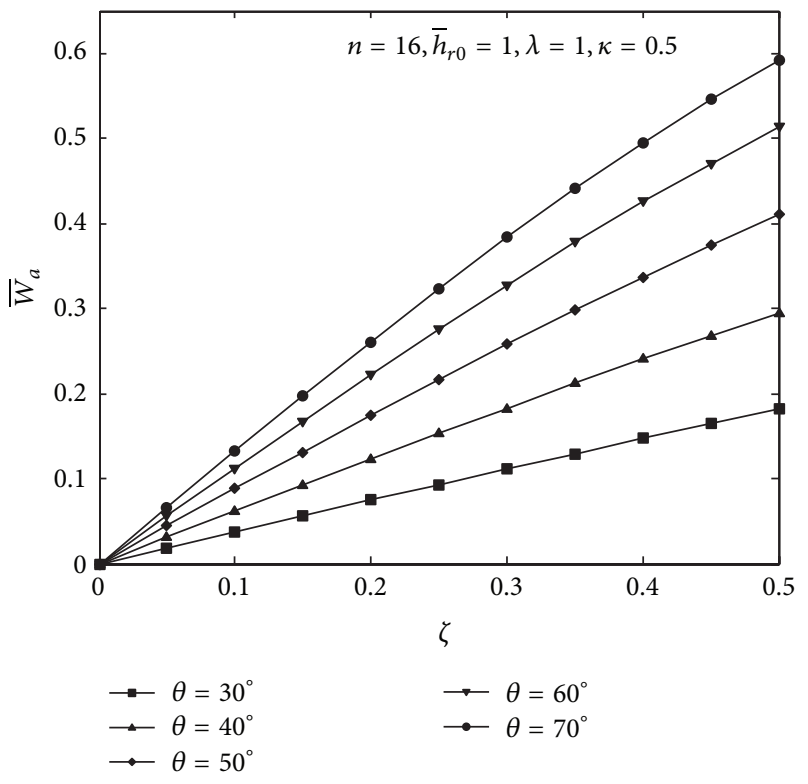

(a) Axial load versus axial displacement

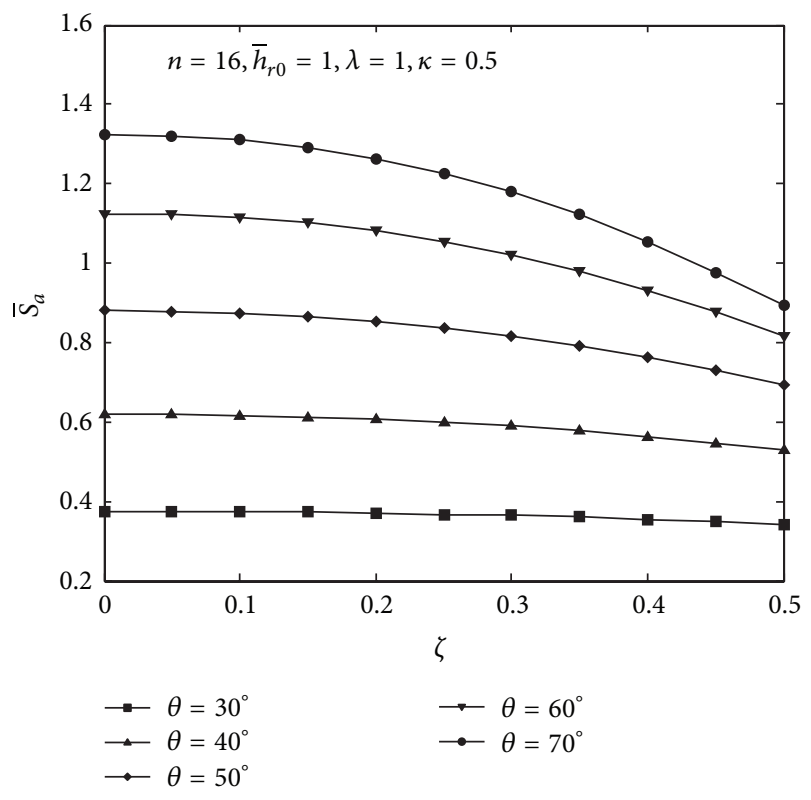

(c) Axial stiffness versus axial displacement

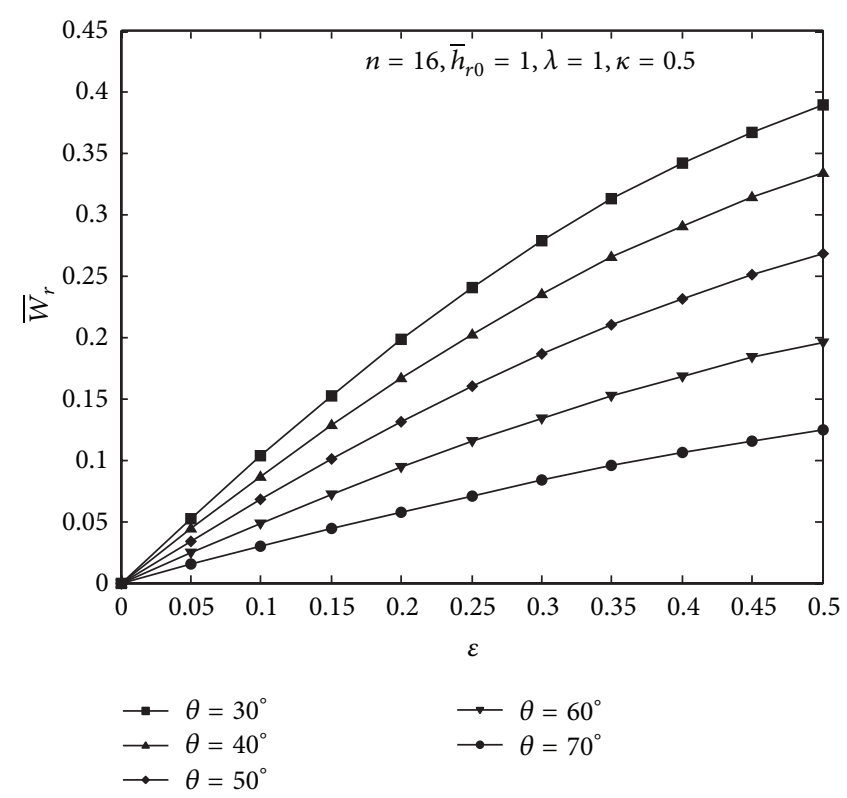

(b) Radial load versus radial displacement

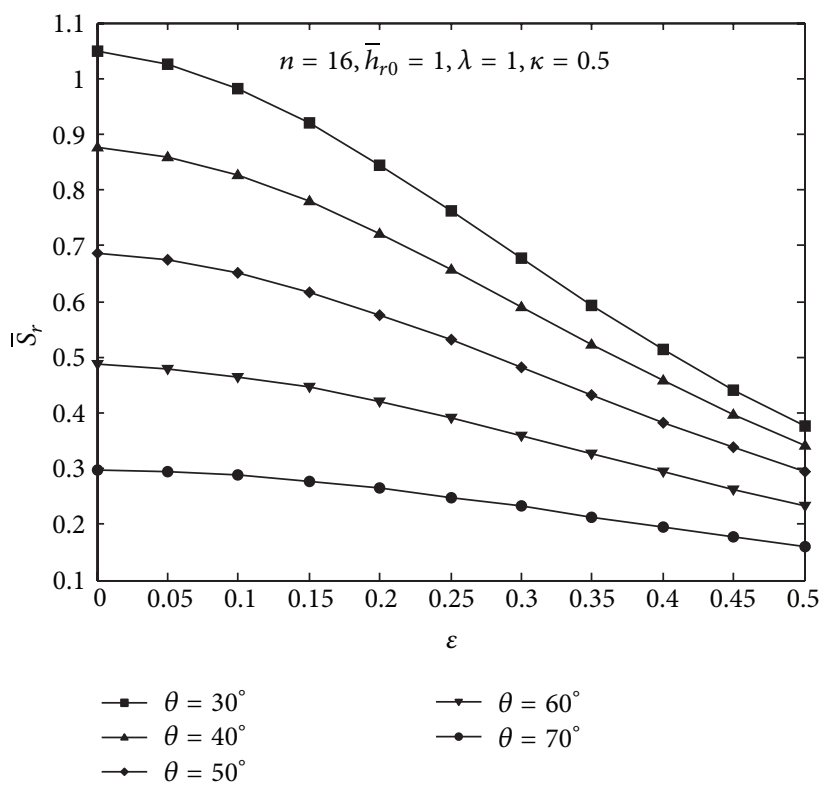

(d) Radial stiffness versus radial displacement

FIGURE 7: Load capacity and static stiffness of bearings with different $\theta$.

area of the bearing. However, a large number of pockets are useful to create excellent averaging effects. For the designed bearing has a large ratio of diameter to length, $n=16$ is adopted in the designed research. The influences of the above-mentioned parameters on the load carrying capacity and stiffness are discussed in this section.

4.1. Load Capacity and Stiffness at Different Semicone Angles $\theta$. Figure 7 shows the load capacity and the stiffness at various dimensionless displacements in the axial and the radial direction, respectively. It is noticed that, as the semicone angle increases $\left(\theta=30^{\circ}, 40^{\circ}, 50^{\circ}, 60^{\circ}\right.$, and $\left.70^{\circ}\right)$, there is a significant reduction in radial load capacity and a considerable increment in axial load capacity, and the stiffness varies in the same trend. The stiffness gets the peak value when the rotor is at the initial place; that is, $\zeta=0$ and $\varepsilon=0$. Designers can select an appropriate semicone angle according to the practice requirement. If both the axial and the radial load capacity are important, a semicone angle around $40^{\circ}$ to $50^{\circ}$ is advisable. In the following sections, simulations were performed at $\theta=50^{\circ}$. 


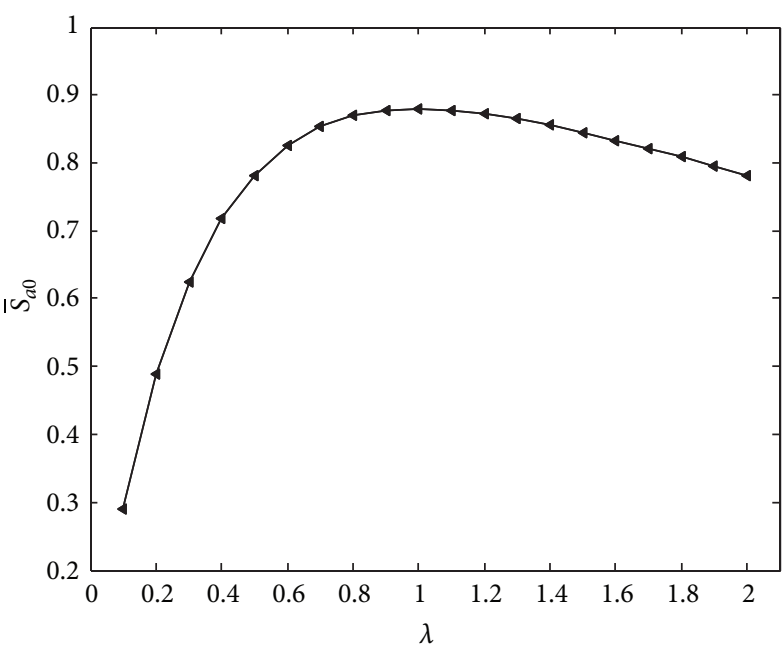

(a) Axial initial stiffness

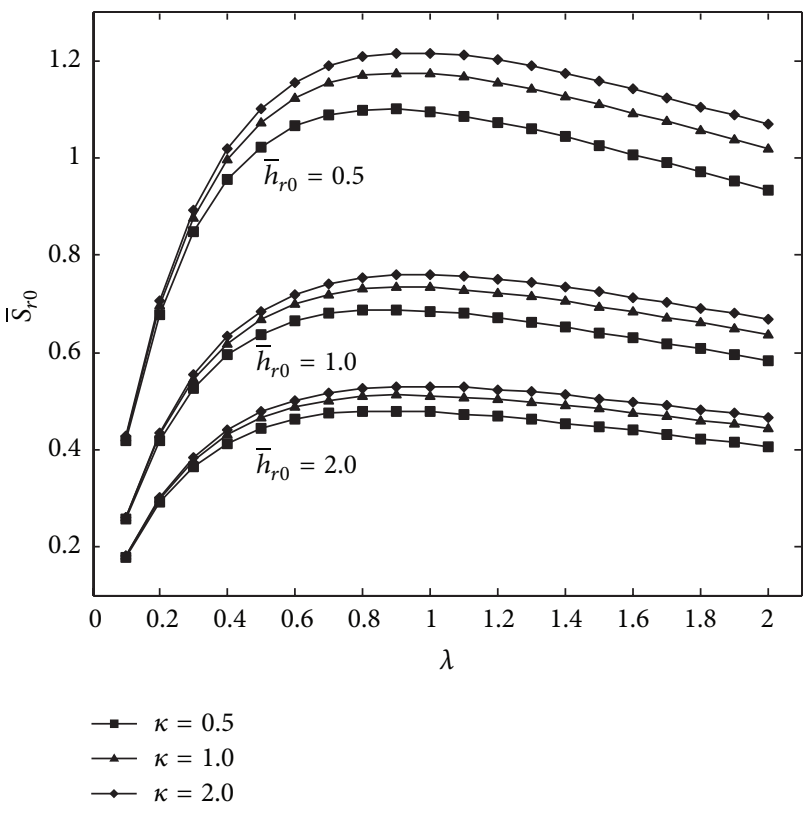

(b) Radial initial stiffness

FIGURE 8: Stiffness versus designed resistance ratio.

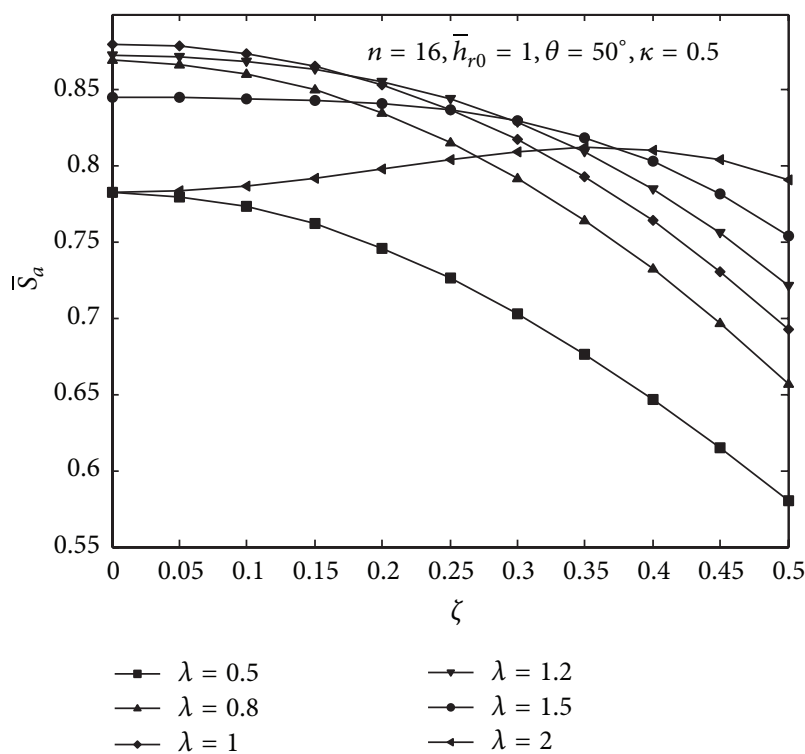

(a) Axial stiffness versus axial displacement

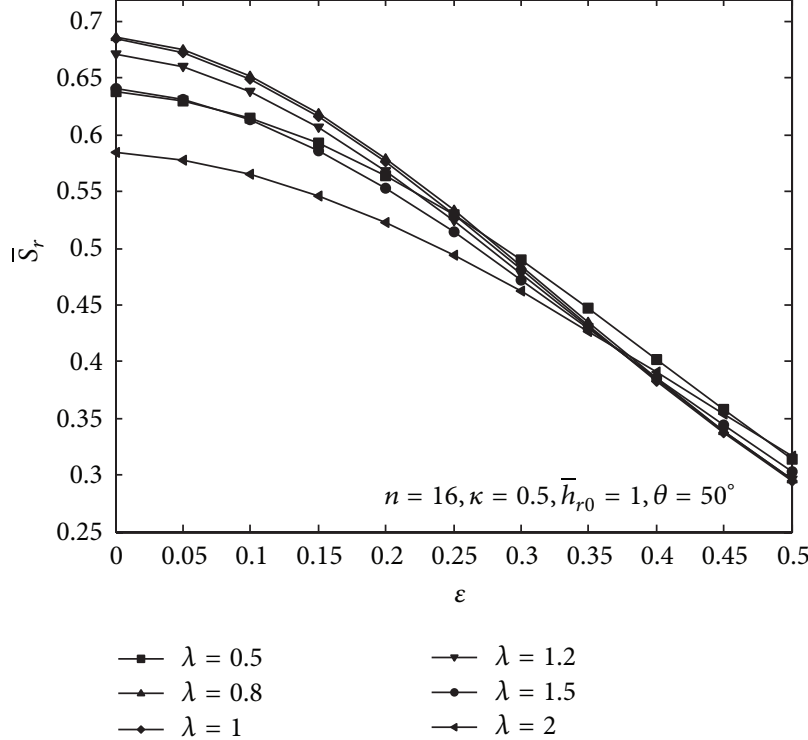

(b) Radial stiffness versus radial displacement

FIGURE 9: Static stiffness of bearings with different $\lambda$.

4.2. Influence of Designed Resistance Ratio $\lambda$. The designed resistance ratio $\lambda$ is always regarded as the most important factor. Figure 8 depicts the variation of the initial stiffness coefficients $\bar{S}_{a 0}$ with $\lambda$. When the rotor is displaced in the axial direction, the clearance ratio $\bar{h}_{r 0}$ and the inner resistance ratio $\kappa$ do not affect the fluid film stiffness $\bar{S}_{a}$, and $\bar{S}_{a 0}$ achieves the maximum value when $\lambda=1$. When the rotor is displaced in the radial direction, the fluid film stiffness $\bar{S}_{r}$ is affected by all the design parameters. As shown in Figure $8(\mathrm{~b}), \bar{S}_{r 0}$ achieves the optimal value when $\lambda$ is in the interval of $0.8 \sim 1.0$. This means that there exists an optimal designed value for $\lambda$, which is around 1. A little value of $\bar{h}_{r 0}$ and a large value of $\kappa$ are favorable to the stiffness.

Figure 9 shows the static stiffness versus dimensionless displacement curves under different values of $\lambda$ and fixed value of $\bar{h}_{r 0}$ and $\kappa$. The more the deviation from the optimal value of $\lambda$ is, the worse the initial stiffness is. For the bearing with $\lambda=0.5$ and $\lambda=2$, the percentage of reduction of the 


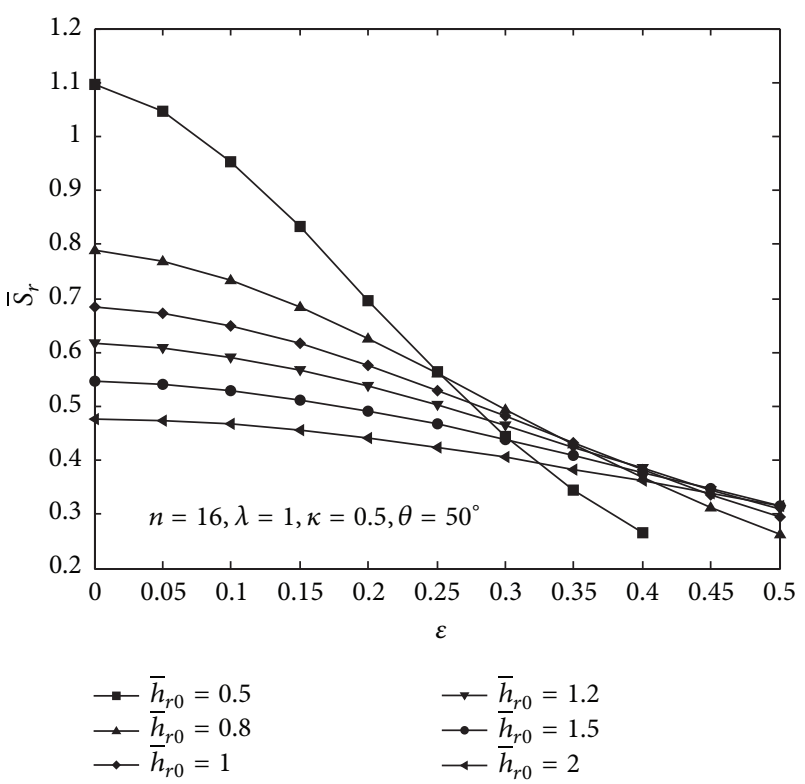

FIGURE 10: Radial static stiffness of bearings with different $\bar{h}_{r 0}$.

initial stiffness in the axial direction is found to be $11.11 \%$ and that in the radial direction is $8.83 \%$ and $13.07 \%$, respectively. However, for the bearing with $\lambda=1$, the stiffness decreases rapidly. Its radial stiffness is lower than the others when $\varepsilon$ is larger than 0.4 . In most cases, the peak value of the stiffness is at the initial location, that is, when the rotor displacement is zero. But when $\lambda=2$, the peak axial stiffness is at the nondimensional axial displacement $\varsigma=0.4$. This unusual evolution can be explained by differentiating the stiffness with respect to the axial displacement.

4.3. Influence of Initial Clearance Ratio $\bar{h}_{r 0}$. Figure 10 depicts the variation of radial stiffness with eccentricity in the condition that the designed resistance ratio $\lambda=1$ and the inner resistance ratio $\kappa=0.5$. Compared with a bearing having $\bar{h}_{r 0}=1$, the bearing with $\bar{h}_{r 0}=0.5$ can achieve an initial radial stiffness of $60.0 \%$ larger. However, the stiffness decreases much more rapidly when $\bar{h}_{r 0}=0.5$. Furthermore, a very little value of $\bar{h}_{r 0}$ is not advisable in practice because the designed resistance ratio $\lambda$ has a three-power relationship with it.

4.4. Influence of Inner Resistance Ratio $\kappa$. Figure 11 depicts the influence of $\kappa$ on the radial stiffness. To avoid the diffusion effect, drain grooves are sometimes fabricated between the adjacent bearing pockets to make a multipad bearing, in which $\kappa$ is infinity. The curves indicate that large value of $\kappa$ is favorable to the bearing stiffness, which is accordant with the knowledge that the lubricant flow between the pockets decreases the bearing stiffness [19]. As $\kappa=R_{l 0} / R_{b 0}$, a larger value of $\kappa$ means that the flow resistance between the pockets is larger; thus, the flow across the inner land is less, which is favorable to the bearings stiffness. Compared with that of a bearing with $\kappa=1$, the initial radial stiffness of a multipad

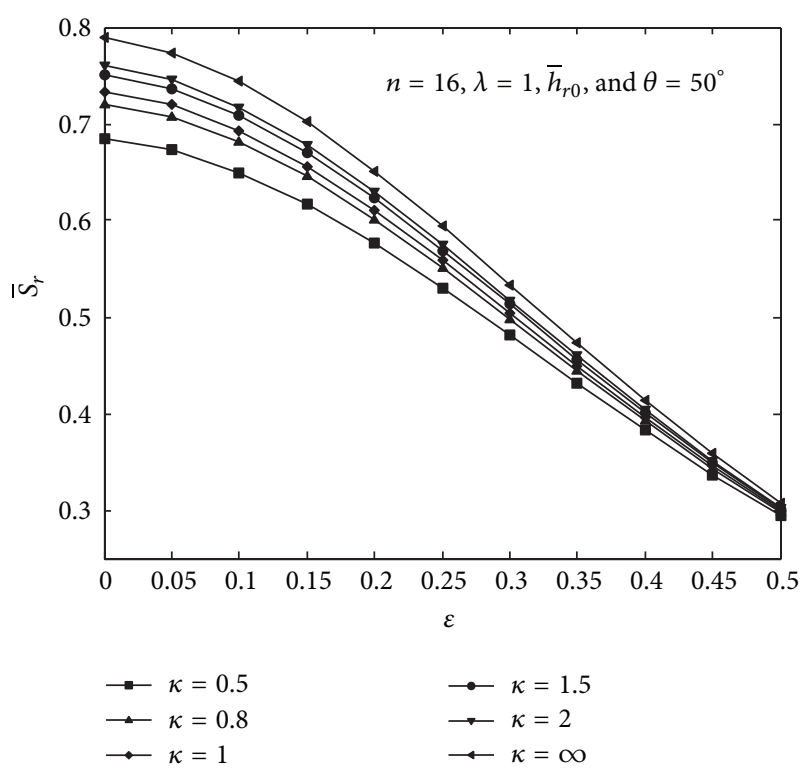

FIGURE 11: Radial static stiffness of bearings with different $\kappa$.

TABLE 1: Main parameters of the manufactured bearing.

\begin{tabular}{lc}
\hline Parameter/Unit & Value \\
\hline Average diameter/mm & 236 \\
Length diameter ratio & 0.14 \\
Semicone angle $/^{\circ}$ & 50 \\
Pocket number & 16 \\
Bearing clearance/mm & 0.04 \\
Design resistance ratio & 1.0 \\
Initial clearance ratio & 1.0 \\
Inner resistance ratio & 12.7 \\
\hline
\end{tabular}

bearing is $7.96 \%$ larger. It means that there exists a limit of $\bar{S}_{r}$, so a very large value of $\kappa$ is not necessary. In design practice, a big value of $\kappa$ means a large width/length ratio of the land region between pockets, which reduces the effective load carrying area of the bearing pockets.

\section{Stiffness Test}

Experimental test of the stiffness has been performed on a prototype bearing, the main geometric parameters of which are listed in Table 1. Figure 12 is the photo of the test setup. The stator is fixed on a $100 \mathrm{~mm}$ thick steel base. Load is applied on the rotor by a rod, which is pushed by a gas cylinder. In the axial test, a block is used to avoid loading at a single point; in the radial test, a plate is fixed on the top surface of the rotor to aid loading. The force is determined by using an Sshaped load cell with a maximum load capacity of $8,000 \mathrm{~N}$ and a resolution of $10 \mathrm{~N}$. The displacement of the rotor is measured using two inductance sensors with a resolution of $0.1 \mu \mathrm{m}$. The experiment and simulation results under supply pressure of 1.0 MPa are plotted in Figure 13. The predicted value of load carrying capacity is larger than that of the tested 


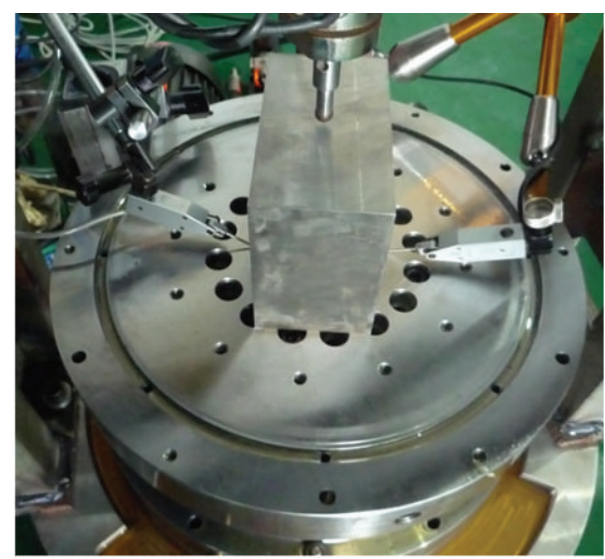

(a)

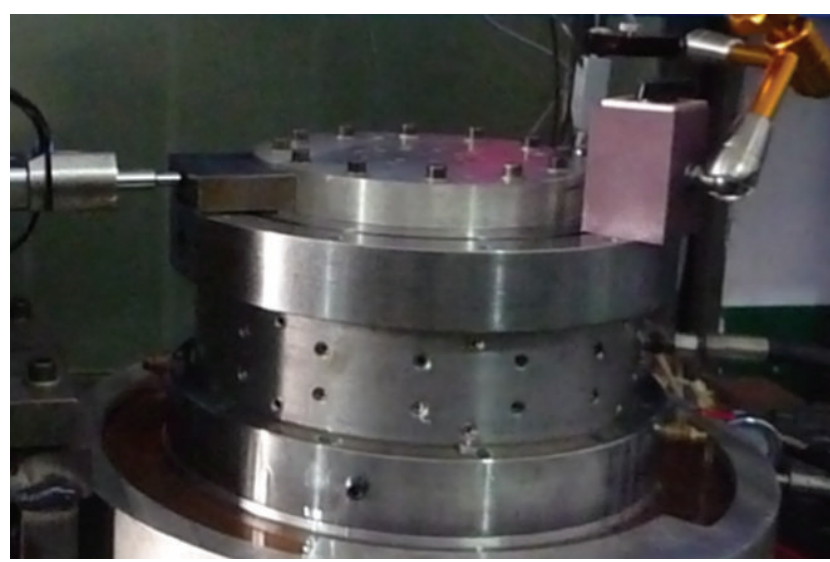

(b)

Figure 12: Photos of the test setup.

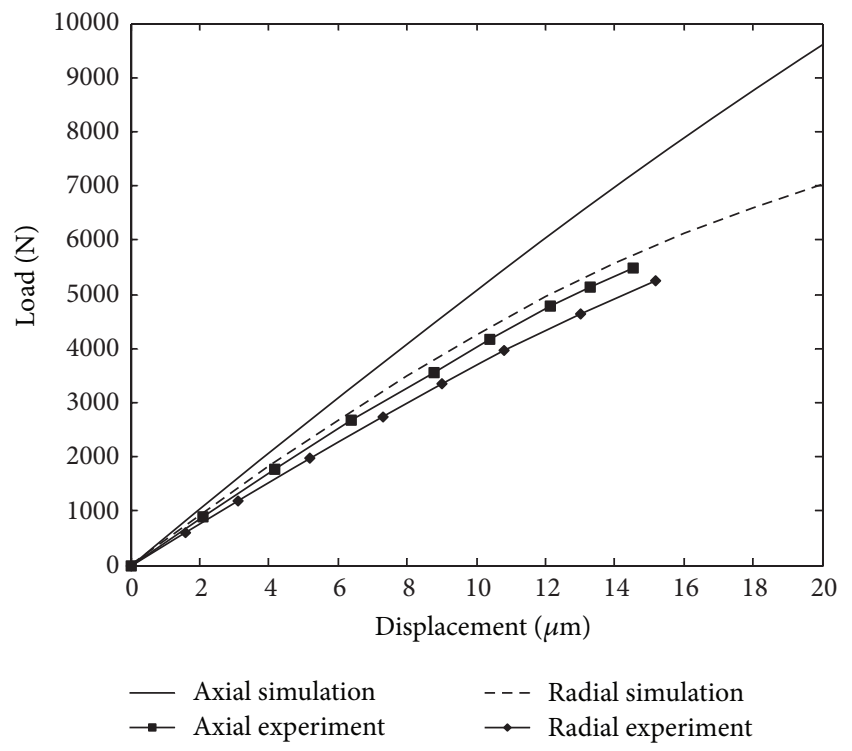

FIGURE 13: Load versus displacement plot of the prototype.

one. The computed initial stiffness is $459 \mathrm{~N} / \mu \mathrm{m}$ in the radial direction and $515 \mathrm{~N} / \mu \mathrm{m}$ in the axial direction. The tested value of initial stiffness is degraded by a percentage of $18 \%$ and $16 \%$ in the radial and the axial direction, respectively. The difference is caused by the complex manufacturing errors, which are not accounted for in the simulation model.

\section{Conclusions}

A self-compensating hydrostatic rotary bearing is designed, and the mathematical model is built based on flow equilibrium. The methodology is validated by experiment, and the influence of the designed parameters on the static performance is discussed. On the basis of the numerically simulated results presented in this study, the following general conclusions may be drawn.
(1) The influencing factors on the bearing static performance are the designed resistance ratio $\lambda$, the inner resistance ratio $\kappa$, the initial clearance ratio $\bar{h}_{b 0}$, and the semiconical angle $\theta$.

(2) The optimum value of the designed resistance ratio $\lambda$ is around 1 , which can be yielded by adjusting the geometry parameters. The bearing with the optimum $\lambda$ has the maximum initial stiffness, but its performance gets worse when the nondimensional displacement is large.

(3) A little value of the clearance rate $\bar{h}_{r 0}$ is beneficial to the static performance in the radial direction. But it is limited in practice by the need to create a reasonable initial resistance ratio $\lambda$.

(4) The inner resistance ratio $\kappa$ affects the radial performance. A large value of $\kappa$ is suggested to reduce the diffusion effect between bearing pockets, but there is a limit for the improvement of the stiffness.

\section{Conflict of Interests}

The authors declare that there is no conflict of interests.

\section{Acknowledgments}

The authors would like to acknowledge the National Nature Science Foundation of China (no. 50805143) and the National Major Project of Science and Technology (2010ZX04001-151).

\section{References}

[1] H. C. Garg, H. B. Sharda, and V. Kumar, "On the design and development of hybrid journal bearings: a review," TriboTest, vol. 12, no. 1, pp. 1-19, 2006.

[2] J. K. Martin, "Design guidelines for hydrostatic journal bearings," Industrial Lubrication and Tribology, vol. 58, no. 3, pp. 135-139, 2006. 
[3] S. B. Malanoski and A. M. Loeb, "The effect of method of compensation on hydrostatic bearing stiffness," Journal of Basic Engineering, Transaction of ASME, vol. 83, pp. 179-187, 1961.

[4] S. C. Sharma, V. Kumar, S. C. Jain, R. Sinhasan, and M. Subramanian, "Study of slot-entry hydrostatic/hybrid journal bearing using the finite element method," Tribology International, vol. 32, no. 4, pp. 185-196, 1999.

[5] N. Singh, S. C. Sharma, S. C. Jain, and S. S. Reddy, "Performance of membrane compensated multirecess hydrostatic/hybrid flexible journal bearing system considering various recess shapes," Tribology International, vol. 37, no. 1, pp. 11-24, 2004.

[6] V. Kumar, S. C. Sharma, and S. C. Jain, "On the restrictor design parameter of hybrid journal bearing for optimum rotordynamic coefficients," Tribology International, vol. 39, no. 4, pp. 356-368, 2006.

[7] D. Gao, D. Zheng, and Z. Zhang, "Theoretical analysis and numerical simulation of the static and dynamic characteristics of hydrostatic guides based on progressive mengen flow controller," Chinese Journal of Mechanical Engineering, vol. 23, no. 6, pp. 709-716, 2010.

[8] D. Gao, J. Zhao, Z. Zhang, and D. Zheng, "Research on the influence of PM controller parameters on the performance of hydrostatic slide for NC machine tool," Journal of Mechanical Engineering, vol. 47, no. 18, pp. 186-194, 2011 (Chinese).

[9] Y. Kang, J.-L. Lee, H.-C. Huang et al., "Design for static stiffness of hydrostatic plain bearings: constant compensations," Industrial Lubrication and Tribology, vol. 63, no. 3, pp. 178-191, 2011.

[10] Y. Kang, C.-H. Chen, H.-H. Lee, Y.-H. Hung, and S.-T. Hsiao, "Design for static stiffness of hydrostatic bearings: single-action variable compensations," Industrial Lubrication and Tribology, vol. 63, no. 2, pp. 103-118, 2011.

[11] F. W. Hoffer, "Automatic fluid pressure balancing system," US Patent 2,449,297, September 1948.

[12] A. H. Slocum, "Self-compensating hydrostatic linear motion bearing," US Patent 5,104,237, April 1992.

[13] A. H. Slocum, "Self-compensating hydrostatic bearing for supporting shafts and spindles and the like for rotary and translational motion and methods therefore," US Patent 5,281,032, January 1994.

[14] A. H. Slocum, P. A. Scagnetti, N. R. Kane, and C. Brunner, "Design of self-compensated, water-hydrostatic bearings," Precision Engineering, vol. 17, no. 3, pp. 173-185, 1995.

[15] K. L. Wasson and A. H. Slocum, "Integrated shaft self- compensating hydrostatic bearing," US Patent 5,700,092, December 1997.

[16] M. S. Kotilainen and A. H. Slocum, "Manufacturing of cast monolithic hydrostatic journal bearings," Precision Engineering, vol. 25, no. 3, pp. 235-244, 2001.

[17] N. R. Kane, J. Sihler, and A. H. Slocum, "A hydrostatic rotary bearing with angled surface self-compensation," Precision Engineering, vol. 27, no. 2, pp. 125-139, 2003.

[18] N. R. Kane, J. Sihler, A. H. Slocum, and M. Walter, "Compact surface self-compensated hydrostatic bearings," US Patent 7,682,082 B2, March 2010.

[19] Y. S. Chen, Hydrostatic Bearing Theory and Design, National Defense Industry Press, Beijing, China, 1980. 

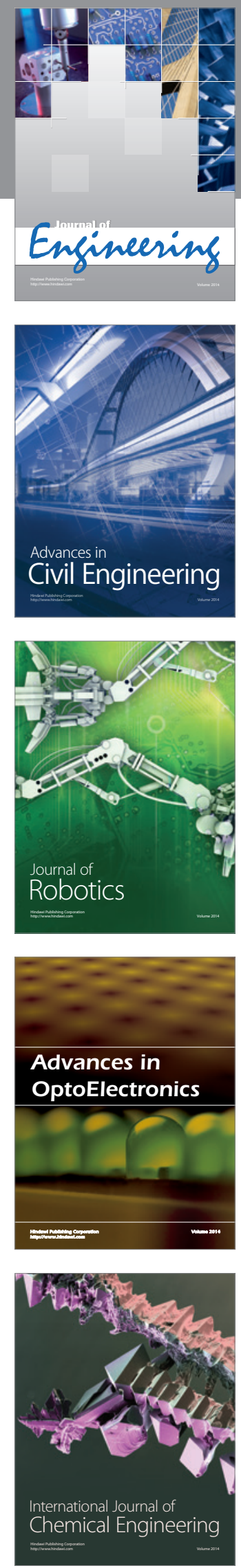

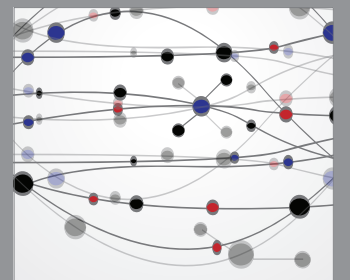

The Scientific World Journal
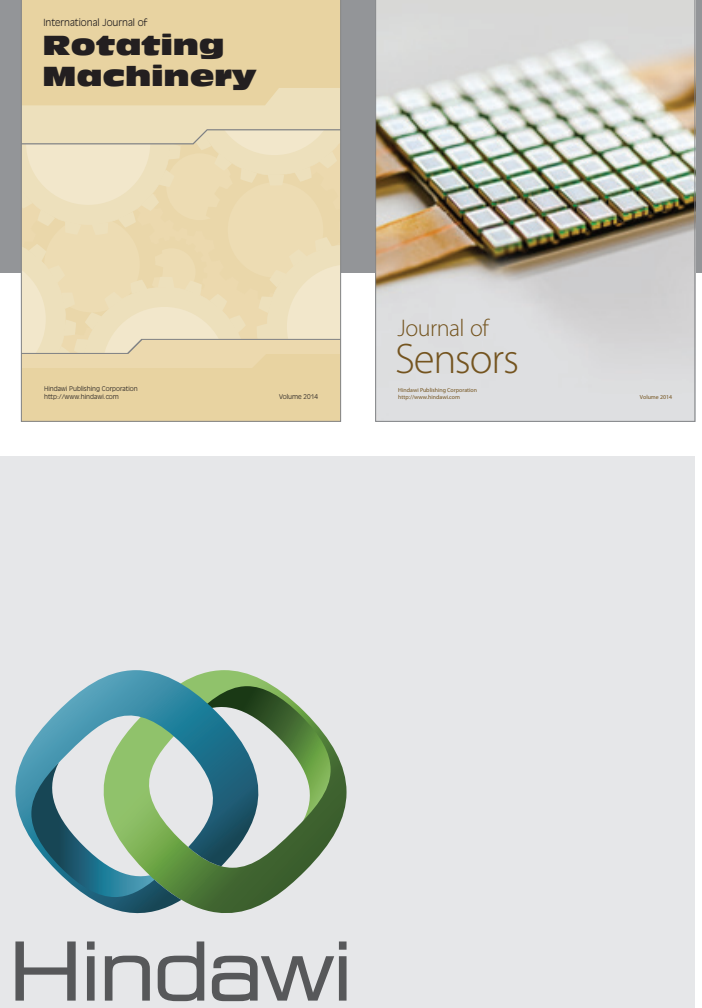

Submit your manuscripts at http://www.hindawi.com
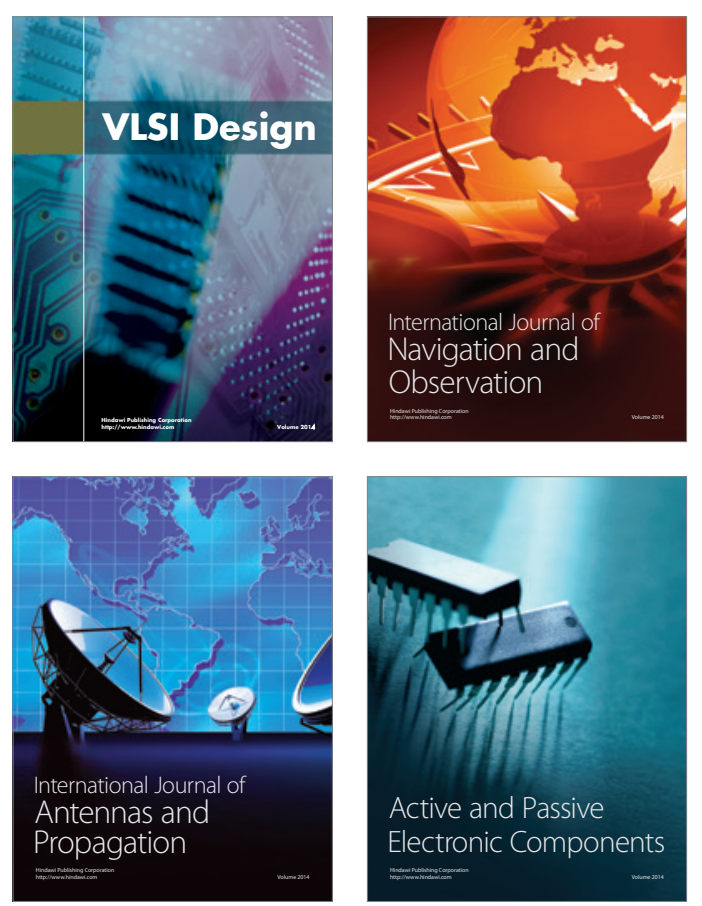
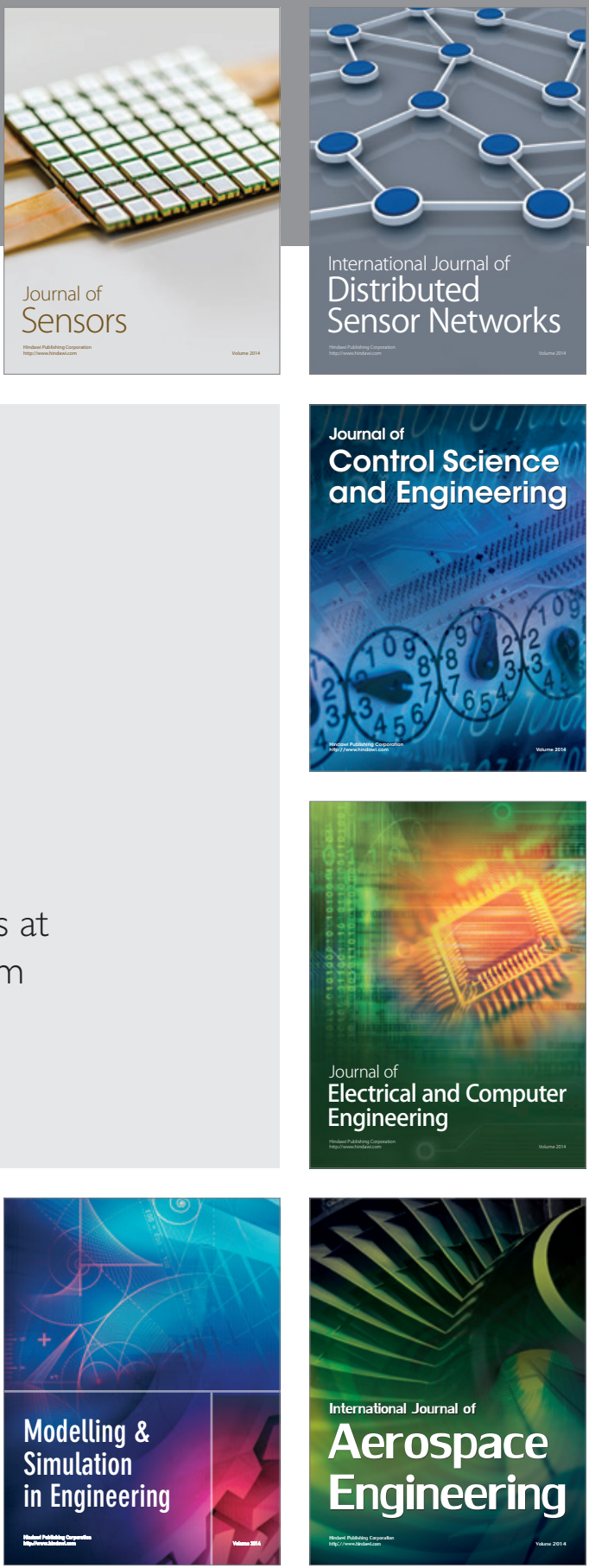

Journal of

Control Science

and Engineering
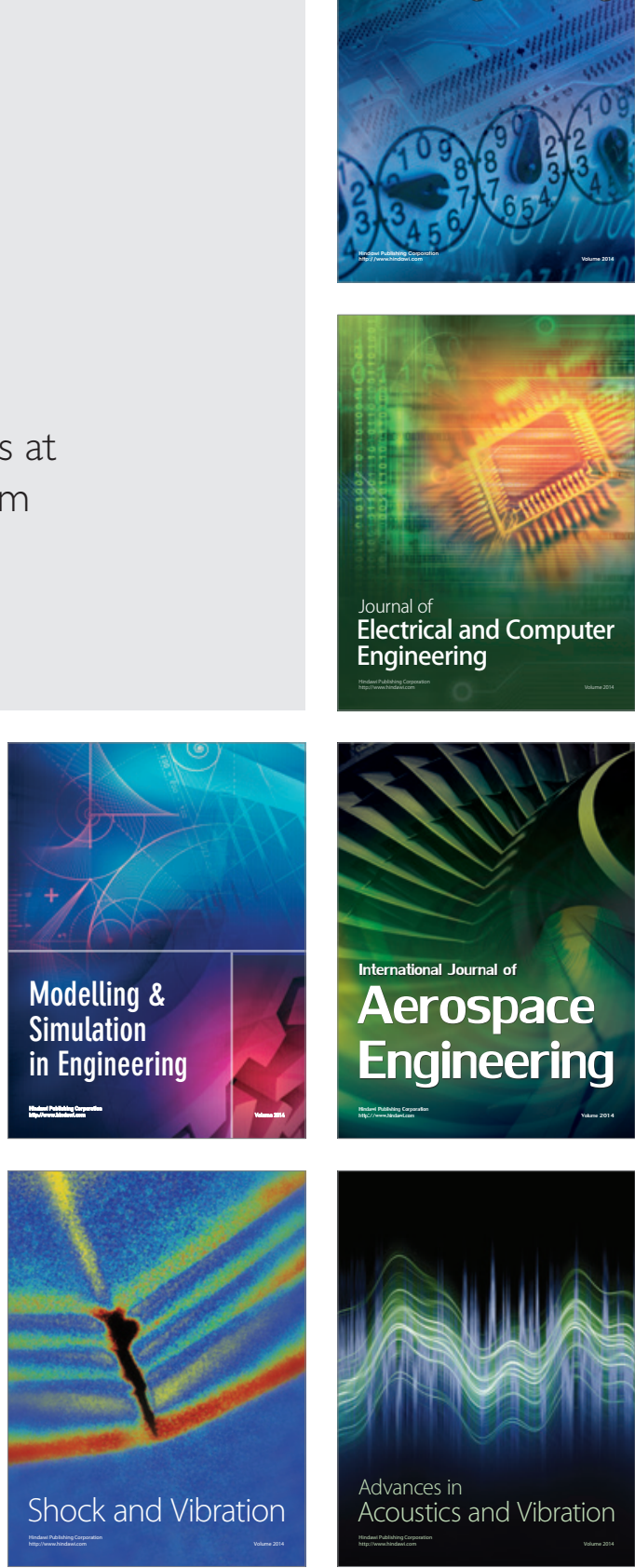